\title{
Correcting Scoliosis in Rett Syndrome
}

\author{
Brett Rocos ${ }^{1}$, Reinhard Zeller ${ }^{1}$ \\ 1. Department of Orthopaedic Surgery, Hospital for Sick Children, Toronto, CAN \\ Corresponding author: Brett Rocos, brettrocos@yahoo.co.uk
}

\section{Abstract \\ Objectives}

Rett syndrome is a rare disorder characterised by severe scoliosis in $80 \%$ of cases. In this retrospective case series, we analysed the radiographic, clinical, and functional outcomes of consecutive patients treated for scoliosis associated with Rett syndrome. We sought to understand the results of the treatment of scoliosis in Rett syndrome and evaluate the need to fuse to the pelvis.

\section{Methods}

A retrospective case series was used to analyse the radiographic, clinical, and functional outcomes of consecutive patients treated for Rett syndrome scoliosis between the ages of 10 and 8 years in a single tertiary paediatric spinal unit. Cases were identified through departmental and neurophysiological records, and patients were excluded if the diagnosis of Rett syndrome was not confirmed.

\section{Results}

Seven eligible cases were identified. At presentation, the mean coronal Cobb angle was $90.9^{\circ}$, mean sagittal Cobb $72.0^{\circ}$, and pelvic obliquity $24.5^{\circ}$. The mean post-operative improvement in coronal Cobb was $53.2^{\circ}$ and pelvic obliquity reduced to $5.8^{\circ}$. These did not change during a mean follow up of 3.5 years. None showed any post-operative complications. Three patients with a mean $16.1^{\circ}$ pelvic obliquity underwent a fusion to L5. The postoperative result in those cases remained stable at 3.5 years mean follow-up and full skeletal maturity.

\section{Conclusion}

Our data suggests that with modern technology, severe curves can be safely treated. Fusion to the pelvis is not necessary in patients with mild, flexible pelvic obliquity.

Categories: Pediatrics, Pediatric Surgery, Orthopedics

Keywords: rett, scoliosis, syndromic scoliosis, neuromuscular scoliosis

Review began 04/14/2021 Review ended 05/26/2021 Published 06/03/2021

(c) Copyright 2021 Rocos et al. This is an open access article distributed under the terms of the Creative Commons Attribution License CC-BY 4.0., which permits unrestricted use, distribution, and reproduction in any medium, provided the original author and source are credited.

\section{Introduction}

Rett syndrome is a rare, neurodegenerative condition which affects young patients, predominantly females, in the first two years of life [1-3]. Investigations show that it is most commonly caused by a mutation in methyl-CpG-binding protein 2 (MECP2), though others have been implicated [1,4-6]. The features of Rett syndrome includes hypotonia, weakness, gross motor disturbance, and typical writhing hand movements $[7,8]$. As an affected child develops, the orthopaedic manifestations of the disease become more apparent, including lower extremity contractures, coxa vara, and scoliosis in up to $83 \%$ of patients [1,9-15]. Common to many of the neuromuscular causes of spinal deformity, a long C-shaped scoliosis is the usual pattern, however, in the case of Rett syndrome, rapid progression in the second decade often occurs $[13,16]$.

The consequence of scoliosis is reduced mobility, reduced sitting balance, and in some severe cases, reduced pulmonary function [17]. Evidence suggests that to limit these, the scoliosis should be treated when the coronal deformity reaches $40^{\circ}[15,16,18]$. It has been suggested that patients with Rett-associated scoliosis should be treated with fusion to the pelvis in order to prevent subsequent progression of deformity correct pelvic obliquity [19]. However, with the additional surgical morbidity attached to fusion to the pelvis, it is sensible to avoid this additional insult where possible, with the potential benefit of preserving ambulation in some cases [5].

In this case series, we sought to describe the severity of spinal and spinopelvic deformity observed in Rett syndrome, the clinical and radiological outcomes of surgery, and compare outcomes between patients who were fused to either the pelvis or L5.

\section{Materials And Methods}

Local ethical board consent was granted. All patients aged between 10 and 18 years with a diagnosis of Rett 


\section{Cureus}

syndrome who underwent posterior spinal fusion for scoliosis were identified using departmental records. The clinical records and digitally stored radiographs (Centricity Enterprise Web V3.0, GE Medical Systems, Arlington Heights, USA) of each patient were reviewed. The immediate post-operative radiograph and the radiograph taken closest to one-year follow up were assessed to evaluate the correction achieved. The most recent follow up radiograph was then compared with the post-operative radiograph to evaluate for any change in spinal alignment. Clinical records were examined to evaluate for the pre- and post-operative mobility, intraoperative neuromonitoring events, surgical complications, or revision procedures.

Data were recorded in Microsoft Excel v 16.32 (Microsoft, Redmont, WA, USA) and analysed using Stata v14 (StataCorp, College Station, TX, USA). Descriptive statistics were used to analyse the radiographic parameters and a two-tailed paired t-test used to assess for changes in curve magnitude in the follow-up period. Categorical data were described using free text.

\section{Results}

Seven female patients met the inclusion criteria with a mean age at surgery of 14.1 years (range 11.0- 17.7). None had undergone any previous hip or spine surgery. Three patients were able to take at least one step and transfer from chair to chair prior to surgery. All showed a neuromuscular pattern to their curve, with a mean coronal Cobb angle of $90.9^{\circ}\left(95 \% \mathrm{CI} 76.0-105.9^{\circ}\right)$, kyphosis of $72.0^{\circ}\left(95 \% \mathrm{CI} 50.7-93.3^{\circ}\right)$ and pelvic obliquity of $24.5^{\circ}\left(95 \%\right.$ CI $\left.11.3-37.8^{\circ}\right)$ (Table 1$)$. Mean follow up was 3.5 years $( \pm 1.65)$.

\begin{tabular}{|l|l|l|l|l|l|}
\hline Patient No & Age at surgery $(\mathrm{yrs})$ & Coronal Cobb $\left(^{\circ}\right)$ & Kyphosis $\left(^{\circ}\right)$ & Pelvic obliquity $\left(^{\circ}\right)$ & Apex of deformity \\
\hline 1 & 17.7 & 120.0 & 68.5 & 45.0 & L2 \\
\hline 2 & 16.7 & 89.0 & 72.5 & 14.5 & T12 \\
\hline 3 & 13.2 & 87.3 & 69.9 & 21.7 & L1 \\
\hline 4 & 11.0 & 104.8 & 100.7 & 38.1 & T10 \\
\hline 5 & 15.6 & 82.7 & 28.5 & 7.3 & T11 \\
\hline 7 & 11.0 & 79.5 & 70.7 & 12.1 & T11 \\
\hline
\end{tabular}

\section{TABLE 1: The demographics and pre-operative radiographic measurements of the cohort}

Four patients were fused from T2 to the pelvis and three to L5 with facetectomy at each level. All underwent posterior instrumented fusion without osteotomy or anterior release. Six had tibial autograft applied to the spine, and two additional iliac crest autograft. All patients were treated with a hybrid construct. The mean length of inpatient stay was 10 days (95\%CI 5.6- 15.0 days).

Four patients showed changes in intraoperative motor evoked potentials (MEPs), each treated with release of traction, elevation of mean arterial pressure and in a single case the temporary release of the correction. No intraoperative complications were encountered, and none showed any changes from their preoperative neurological status as a result of surgery when examined post operatively. The post-operative mean coronal Cobb was $37.7^{\circ}\left(95 \%\right.$ CI $\left.27.9-47.6^{\circ}\right)$, a mean improvement of $53.2^{\circ}(95 \%$ CI $40.5-65.9, \mathrm{p}<0.01$ ) (Table 2). 


\section{Cureus}

\begin{tabular}{|c|c|c|c|c|c|c|c|}
\hline $\begin{array}{l}\text { Patient } \\
\text { no }\end{array}$ & $\begin{array}{l}\text { Ambulating } \\
\text { pre op }\end{array}$ & $\begin{array}{l}\text { Pre-operative } \\
\text { Coronal Cobb ( }\left(^{\circ}\right)\end{array}$ & $\begin{array}{l}\text { Pelvic } \\
\text { obliquity } \\
\left({ }^{\circ}\right)\end{array}$ & $\begin{array}{l}\text { Fused to } \\
\text { pelvis }\end{array}$ & $\begin{array}{l}\text { Post-operative } \\
\left.\text { coronal Cobb ( }{ }^{\circ}\right)\end{array}$ & $\begin{array}{l}\text { Post-operative } \\
\text { pelvic obliquity }\end{array}$ & $\begin{array}{l}\text { Post-operative } \\
\text { ambulation }\end{array}$ \\
\hline 1 & $\mathrm{~N}$ & 120.0 & 45.0 & $Y$ & 44.7 & 2.1 & $\mathrm{~N}$ \\
\hline 2 & $\mathrm{~N}$ & 89.0 & 14.5 & $\mathrm{~N}$ & 61.7 & 10.9 & $Y$ \\
\hline 3 & $Y$ & 87.3 & 21.7 & $\mathrm{~N}$ & 46.9 & 4.4 & $Y$ \\
\hline 4 & $\mathrm{~N}$ & 104.8 & 38.1 & $Y$ & 40.2 & 4.7 & $\mathrm{~N}$ \\
\hline 5 & $Y$ & 82.7 & 7.3 & $Y$ & 20.5 & 10.2 & $\mathrm{Y}$ \\
\hline 6 & $\mathrm{Y}$ & 79.5 & 12.1 & $\mathrm{~N}$ & 43.5 & 1 & Y \\
\hline 7 & $\mathrm{~N}$ & 73.2 & 32.8 & $Y$ & 42.3 & 7 & $\mathrm{~N}$ \\
\hline
\end{tabular}

TABLE 2: The changes in the coronal deformity and ambulation status of each patient

Kyphosis was improved by $35.4^{\circ}$ (95\% CI $13.1-57.7, \mathrm{p}<0.01$ ). Pelvic obliquity was improved to a mean $5.8^{\circ}$ (Table 2). The spinal parameters were unchanged for the duration of follow up regardless of whether the pelvis was included in the construct or not. None of the patients showed any post-operative complications, and all survived to most recent follow up. No patient who was fused to the pelvis showed any change in their ability to ambulate following surgery.

The three patients not fused to the pelvis presented with a moderate flexible pelvic obliquity preoperatively. The residual $5.8^{\circ}$ pelvic obliquity remained unchanged over a mean follow up of 3.5 years and full skeletal maturity at last follow-up (average age 17 years). A single patient of the three showed an improvement in their postoperative mobility (Table 2).

\section{Discussion}

These data suggest that, in selected cases, it may be possible to avoid fusion to the pelvis and prevent further deformity despite the progressive nature of the disease. Furthermore, it suggests that the incidence of postoperative complications is low when posterior fusion with tibial graft is used. A satisfactory radiological result is achieved without anterior release in all cases, and no incidence of neurological compromise is recorded (Figure 1). 


\section{Cureus}
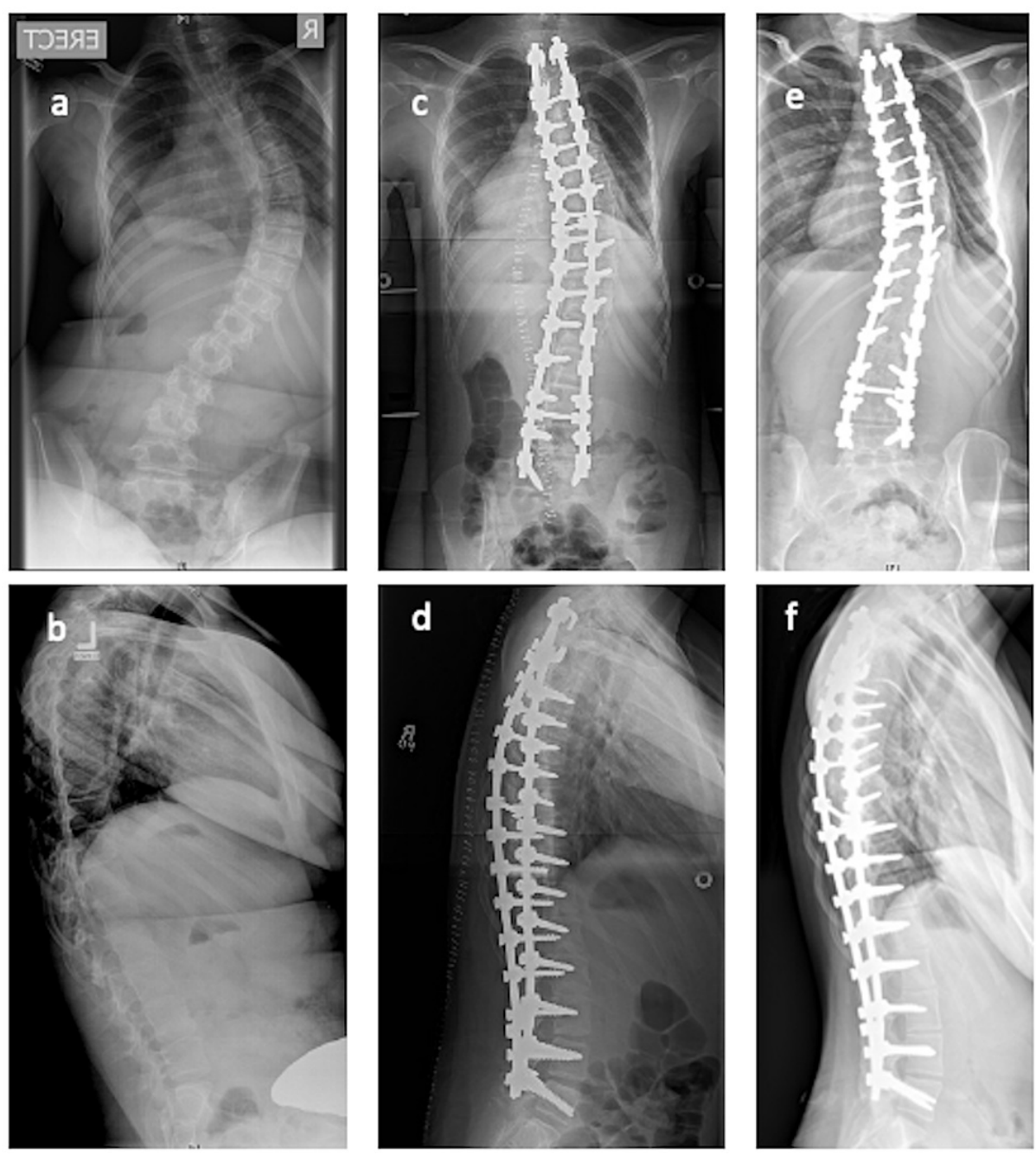

\section{FIGURE 1: Plain radiographs of a 11-year-old female patient}

a) AP and b) lateral plain radiograph of an 11-year-old female patient with a coronal angular deformity of $79.5^{\circ}$ and kyphosis of $70.7^{\circ}$ and pelvic obliquity of $12.1^{\circ}$. c) AP and d) lateral post-operative radiographs showing posterior instrumented fusion of T2 to L5 with a coronal angular deformity of $23.1 \circ$, kyphosis of $43.5^{\circ}$ and pelvic obliquity of $1^{\circ}$. This correction is maintained at five years in e) AP and f) lateral radiographs.

It would be reasonable to recommend that patients with fixed pelvic obliquity, a history of hip surgery, and a declining neurologic status should undergo fusion to the pelvis to ensure a stable sitting posture. Although these data are unable to identify criteria which guarantee a successful outcome after a posterior spinal fusion not extending to the pelvis, it could be hypothesised that strategy is reasonable in patients who retain some control over the lumbosacral junction (for example, controlled swaying of the trunk) with symmetrical hip range of motion and some retention of motor control. In this series, patients were fused to the pelvis when there was a preceding rapid decline in neurological function with a lethargic presentation and uncontrolled, treatment-resistant daily seizures.

The clinical significance of these results is in preventing surgical morbidity. By avoiding fusion to the pelvis in almost half of the cases, we have shown that the overall outcome is satisfactory, and suggested that this strategy will aid in preserving a patient's ability to independently mobilise. Furthermore, these findings provide evidence that tibial grafting is useful in achieving fusion in these complex cases, as there is no incidence of loose hardware or revision for pseudarthrosis seen in this series.

Given that the evidence supports tackling spine deformity in paediatric patients when it reaches $40^{\circ}$, these patients in this cohort could reasonably be defined as being at the severe end of the spectrum $[3,15,16]$. This is supported by Riise et al. and Koop et al., who both identify severe scoliosis in Rett syndrome as one with a long curve which the pelvis becomes oblique, and Killian et al. who showed that severe scoliosis in Rett syndrome correlated with a reduced ability to ambulate and use one's hands $[13,19,20]$. The literature does not contain any studies which evaluate the corrections possible in Rett syndrome. This may be because of its rarity, or the technical challenges which have historically been present in managing these patients, the perioperative morbidity, and difficulty in monitoring their neurological status during the procedures $[21,22]$. 
Nonetheless, we have shown that a safe correction can be achieved and that modern techniques in neuromonitoring can facilitate its accomplishment.

Alongside the prevention of deterioration, patients and their families derive benefit from surgery in severe scoliosis associated with Rett syndrome. Kerr et al. showed that $84 \%$ of families thought that surgery had a positive effect on the family unit [15]. In 2016, Downs et al. also showed that surgery appears to lengthen life in this patient group, particularly in reducing the risk of respiratory tract infection, though in contrast. Pisano et al. report a patient who did not survive extension of fusion to the pelvis, and Gabos et al. showed a $63 \%$ rate of respiratory and $37 \%$ gastrointestinal complication rate in these patients $[17,23,24]$.

This study is limited by the small number of patients treated for Rett syndrome, and the challenges in consistent radiographic technique in non-ambulatory patients. Although we have seen no loss to follow up, extending the follow up period into adulthood would be useful in understanding how mobility changes following surgery in later life.

\section{Conclusions}

Scoliosis is the most common orthopaedic manifestation of Rett syndrome, and is one that should be considered for surgical treatment early in its development. Our data suggests that with modern technology, severe curves can be safely treated, that fusion to the pelvis is not always necessary, and in some selected cases, a fusion to L5 is sufficient and may be important in preserving patient mobility post operatively.

\section{Additional Information \\ Disclosures}

Human subjects: Consent was obtained or waived by all participants in this study. Hospital for Sick Children Research Ethics Board issued approval 1000069681. Approved- Active. Animal subjects: All authors have confirmed that this study did not involve animal subjects or tissue. Conflicts of interest: In compliance with the ICMJE uniform disclosure form, all authors declare the following: Payment/services info: All authors have declared that no financial support was received from any organization for the submitted work. Financial relationships: All authors have declared that they have no financial relationships at present or within the previous three years with any organizations that might have an interest in the submitted work. Other relationships: Reinhard Zeller receives fellowship support from Spine Vision.

\section{References}

1. Ager S, Fyfe S, Christodoulou J, Jacoby P, Schmitt L, Leonard H: Predictors of scoliosis in Rett syndrome. J Child Neurol. 2006, 21:809-813. 10.1177/08830738060210091501

2. The Rett Syndrome Diagnostic Criteria Work Group: Diagnostic criteria for Rett syndrome. Ann Neurol. 1988, 23:425-28. 10.1002/ana.410230432

3. Downs J, Bergman A, Carter P, et al.: Guidelines for management of scoliosis in Rett syndrome patients based on expert consensus and clinical evidence. Spine. 2009, 34:E607-17. 10.1097/BRS.0b013e3181a95ca4

4. Amir RE, Fang P, Yu Z, et al.: Mutations in exon 1 of MECP2 are a rare cause of Rett syndrome . J Med Genet. 2005, $42: \mathrm{e} 15$.

5. Laurvick CL, de Klerk N, Bower C, et al.: Rett syndrome in Australia: a review of the epidemiology . J Pediatr. 2006, 148:347-52. 10.1016/j.jpeds.2005.10.037

6. Percy AK, Lee HS, Neul JL, et al.: Profiling scoliosis in Rett syndrome. Pediatr Res. 2010, 67:435-9. 10.1203/PDR.0b013e3181d0187f

7. Lidström J, Stokland E, Hagberg B: Scoliosis in Rett syndrome: clinical and biological aspects . Spine. 1994, 19:1632-5. 10.1097/00007632-199407001-00013

8. Neul JL, Kaufmann WE, Glaze DG, et al.: Rett syndrome: revised diagnostic criteria and nomenclature . Ann Neurol. 2010, 68:944-50.10.1002/ana.22124

9. Guidera KJ, Borrelli J Jr, Raney E, Thompson-Rangel T, Ogden JA: Orthopaedic manifestations of Rett syndrome. J Pediatr Orthop. 1991, 11:204-8. 10.1097/01241398-199103000-00013

10. Hennessy MJ, Haas RH: The orthopedic management of Rett syndrome. J Child Neurol. 1988, 3:S43-7. 10.1177/0883073888003001s09

11. Ager S, Downs J, Fyfe S, Leonard H: Parental experiences of scoliosis management in Rett syndrome . Disabil Rehabil. 2009, 31:1917-24. 10.1080/09638280902846392

12. Bassett GS, Tolo VT: The incidence and natural history of scoliosis in Rett syndrome . Dev Med Child Neurol. 1990, 32:963-6. 10.1111/j.1469-8749.1990.tb08118.x

13. Riise R, Brox JI, Sorensen R, Skjeldal OH: Spinal deformity and disability in patients with Rett syndrome . Dev Med Child Neurol. 2011, 53:653-7. 10.1111/j.1469-8749.2011.03935.x

14. Tanguy A: Orthopedic aspects of Rett syndrome [Article in French]. Ann Pediatr. 1993, 40:237-241.

15. Kerr AM, Webb P, Prescott RJ, Milne Y: Results of surgery for scoliosis in Rett syndrome. J Child Neurol. 2003, 18:703-8. 10.1177/08830738030180101201

16. Huang TJ, Lubicky JP, Hammerberg KW: Scoliosis in Rett syndrome. Orthop Rev. 1994, 23:931-937.

17. Downs J, Torode I, Wong K, et al.: Surgical fusion of early onset severe scoliosis increases survival in Rett syndrome: a cohort study. Dev Med Child Neurol. 2016, 58:632-8. 10.1111/dmcn.12984

18. Downs J, Young D, de Klerk N, Bebbington A, Baikie G, Leonard H: Impact of scoliosis surgery on activities of daily living in females with Rett syndrome. J Pediatr Orthop. 2009, 29:369-74. 


\section{Cureus}

10.1097/BPO.0b013e3181a53b41

19. Koop SE: Scoliosis and Rett syndrome. Dev Med Child Neurol. 2011, 53:582-3. 10.1111/j.14698749.2011.03960.x

20. Killian JT, Lane JB, Lee HS, et al.: Scoliosis in Rett syndrome: progression, comorbidities, and predictors . Pediatr Neurol. 2017, 70:20-5. 10.1016/j.pediatrneurol.2017.01.032

21. Master DL, Thompson GH, Poe-Kochert C, Biro C: Spinal cord monitoring for scoliosis surgery in Rett syndrome: can these patients be accurately monitored?. J Pediatr Orthop. 2008, 28:342-6. 10.1097/BPO.0b013e318168d194

22. Rumbak DM, Mowrey W, Schwartz SW, Sarwahi V, Djukic A, Killinger JS, Katyal C: Spinal fusion for scoliosis in Rett syndrome with an emphasis on respiratory failure and opioid usage. J Child Neurol. 2016, 31:153-8. $10.1177 / 0883073815585352$

23. Pisano AJ, Wagner SC, Helgeson MD, Jex JW: Multiple vertebral dislocation events after fusion for scoliosis in Rett syndrome. Spine J. 2015, 15:e61-2. 10.1016/j.spinee.2015.07.457

24. Gabos PG, Inan M, Thacker M, Borkhu B: Spinal fusion for scoliosis in Rett syndrome with an emphasis on early postoperative complications. Spine. 2012, 37:E90-4. 10.1097/BRS.0b013e3182404698 